\title{
Investment Casting of Gold Jewellery
}

\section{TEMPER ATURE CHANGES OCCURRING IN THE METAL AND THE INVESTMENT: THEIR MEASUREMENT AND IMPORTANCE}

\author{
Dieter Ott and Christoph J. Raub \\ Forschungsinstitut für Edelmetalle und Metallchemie, Schwäbisch Gmünd, Federal Republic of Germany
}

Changes in temperature which take place during pouring of a melt and flow into the mould vary greatly, and also depend on the casting technique used. Understanding these changes is important for optimum casting practice.

Observations of the temperature changes occurring in the metal and in the investment during casting show that the temperature losses in the melt during pouring and penetration of the mould are very different. They are determined both by the conditions under which the melt is poured and by the casting technique used. This implies that many factors affect the cooling and solidification of the melt and that studies of these processes should give results showing a considerable scatter. Although this expectation has been confirmed, the results of the experiments described below nevertheless permit the drawing of conclusions which should prove of value in casting practice.

There is virtually no published information available concerning either the course of solidification of the molten metal or the conduction of heat by the investment during the casting of carat gold jewellery. Preliminary experiments were carried out in this connection using thermal probes made of wire $0.3 \mathrm{~mm}$ in diameter, but the results were not reliable, because of the effects of the relatively large size of the probes. Through the use of smaller probes the measurements were much improved and the following investigations made possible:

- Determination of the thermal conductivity of the investment.

- Studies of the cooling and solidification behaviour of spherical castings with various ratios of surface area to volume.

- Determination of the temperature changes occurring in the investment during casting.

Fig. 1 Schematic diagram of the equipment for measurement of thermal conductivity by the method given in DIN 51046

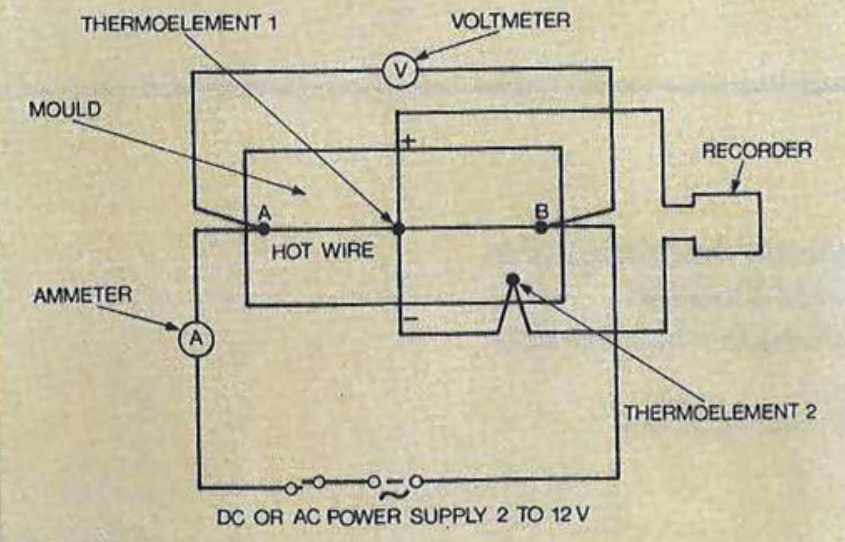

- Studies of the cooling of the molten metal while being poured. Experimental Details

Measurements of the thermal conductivity of the investment were carried out by a standard procedure (DIN 51046, Part 1) for the testing of ceramic materials. The experimental arrangements are illustrated schematically in Figure 1. Temperature changes were measured using a hot wire (A-B), $95 \mathrm{~mm}$ in length with constant heat output, which was embedded in a cylindrical mould $90 \mathrm{~mm}$ in diameter and $110 \mathrm{~mm}$ long. The investment was burnt out as usual at $730^{\circ} \mathrm{C}$ and then cooled to $600^{\circ} \mathrm{C}$. In order to achieve as uniform a heat distribution as possible in the material, and therefore a small temperature difference between the two temperature probes 1 and 2 , the test block of investment was well insulated with a ceramic mat. The necessary voltage was supplied by a highly stable A.C. source. Suitable screening and power leads ensured protection from disturbance factors. The variations in potential arising from the two temperature probes were measured and displayed on a $y-t$ recorder.

The cooling of the cast metal was studied using spiral castings of the type described recently in this journal (Gold Bull. 1985, 18, (2), 58-68) in addition to spherical castings. Because of their geometry, however, spherical castings were found to be better suited for the purpose. The cooling characteristics of these can be related to the respective ratios $(R)$ of their surface areas to their surface volumes, i.e. by $R=3 / r$, where $r$ is the radius of the sphere. The sizes of the spheres which were cast and their $R$-values are as follows:

\begin{tabular}{c|c} 
Diameter of sphere & R-value \\
\hline $15 \mathrm{~mm}$ & 0.4 \\
$10 \mathrm{~mm}$ & 0.6 \\
$7 \mathrm{~mm}$ & 0.86
\end{tabular}

The spheres were cast, just like gold jewellery items, by attaching the spherical wax models to the stem of a casting tree. The temperature measurement probes were made of $0.2 \mathrm{~mm}$ diameter wire and had an overall diameter of $1 \mathrm{~mm}$. They were located at the centres of the spherical wax models. On account of the small diameter of the wire the relatively high temperature being measured and the insulation of the wires with glass fibre material, the probes could not be used in more than the one experiment.

The castings were made using the same yellow 18-carat gold alloy ( 75 gold/16 silver/9 copper weight per cent) as was used in the studies described previously loc. cit.).

Investigations of the temperature changes occurring in the 
Hostment during the solidification of castings were also carried out using spherical castings of the dimensions recorded above. Additional temperature measurement probes were, however, sited in the investment medium at three positions from 1 to $9 \mathrm{~mm}$ from the surfaces of the spherical wax models.

When following the falls in temperature which occurred during the casting of spirals, (diameter, $2 \mathrm{~mm}$ ) the wax models of the latter were attached at right angles to the trunk of the casting tree, about $70 \mathrm{~mm}$ away from the point of entry of the molten metal. Temperature measurement probes were sited at distances of 90 and $150 \mathrm{~mm}$ along the spiral. The temperature of melt as it entered the mould was also measured and changes recorded.

\section{Experimental Results}

Thermal Conductivity of the Investment Medium

The thermal conductivity of a material can be calculated(see DIN 51046) using the equation:

$$
\begin{aligned}
\lambda & =\frac{\mathrm{U} . \mathrm{I}}{4 \pi \mathrm{l}} \cdot \frac{\ln \left(\mathrm{t}_{2} / \mathrm{t}_{1}\right)}{\mathrm{T}_{2}-\mathrm{T}_{1}}\left[\mathrm{~W} \mathrm{~K}^{-1} \mathrm{~m}^{-1}\right] \\
\lambda & =\text { Thermal conductivity } \\
U & =\text { Voltage }(\mathrm{V}) \\
I & =\text { Electrical current }(\mathrm{A}) \\
l & =\text { Length of the heated measuring wire }(\mathrm{m}) \\
t_{2}, t_{1} & =\text { Times }(\mathrm{s}), \text { elapsed since the heating current was switched }
\end{aligned}
$$
on

$$
T_{2}, T_{1}=\text { Temperatures }(\mathrm{K}) \text { measured at times } t_{2} \text { and } t_{1}
$$
and $\frac{\ln \left(\mathrm{t}_{2} / \mathrm{t}_{1}\right)}{\Delta \mathrm{T}}$ (where $\left.\triangle \mathrm{T}=\mathrm{T}_{2}-\mathrm{T}_{1}\right)$ can be determined from the slope of the linear function $\mathrm{d}(\mathrm{nnt})=\mathrm{B} \cdot \mathrm{dT}$

$B$ wascalculated from the observed values by regression analysis using the method of least squares. In none of the series of observations made did the function (2) deviate significantly from linearity. The correlation coefficient was $>0.99$ throughout.

The measurements made at $600{ }^{\circ} \mathrm{C}$ on a gypsum-bonded investment (Holben Davis), yielded an average value for its thermal conductivity of $0.50 \mathrm{~W} / \mathrm{mK}$, with a standard deviation of 0.05 $\mathrm{W} / \mathrm{mK}$ in 13 experiments. The thermal conductivity of the investment is thus less than that of firebrick, at $600^{\circ} \mathrm{C}(0.6$ to 0.9 $\mathrm{W} / \mathrm{mK}$ ) and is similar to that of most heat insulators.

\section{Cooling of the Cast Metal Spheres}

Typical cooling curves for spheres formed at a casting temperature $\left(T_{G}\right)$ of 1000 to $1050^{\circ} \mathrm{C}$ and investment temperatures $\left(T_{K}\right)$ of 400 , 500 and $600{ }^{\circ} \mathrm{C}$ respectively are given in Figure 2 . In all the tests the following behaviour was characteristic:

After rising for a short period of 0.1 to $0.3 \mathrm{~s}$, the temperature reached a maximum and thereafter fell rapidly to the point at which solidification of the metal began. This could be recognised by a sharp change in the cooling curve at 910 to $930{ }^{\circ} \mathrm{C}$. The actual temperatures at which solidification began depended partly upon the degrees of supercooling which occurred. The point at which

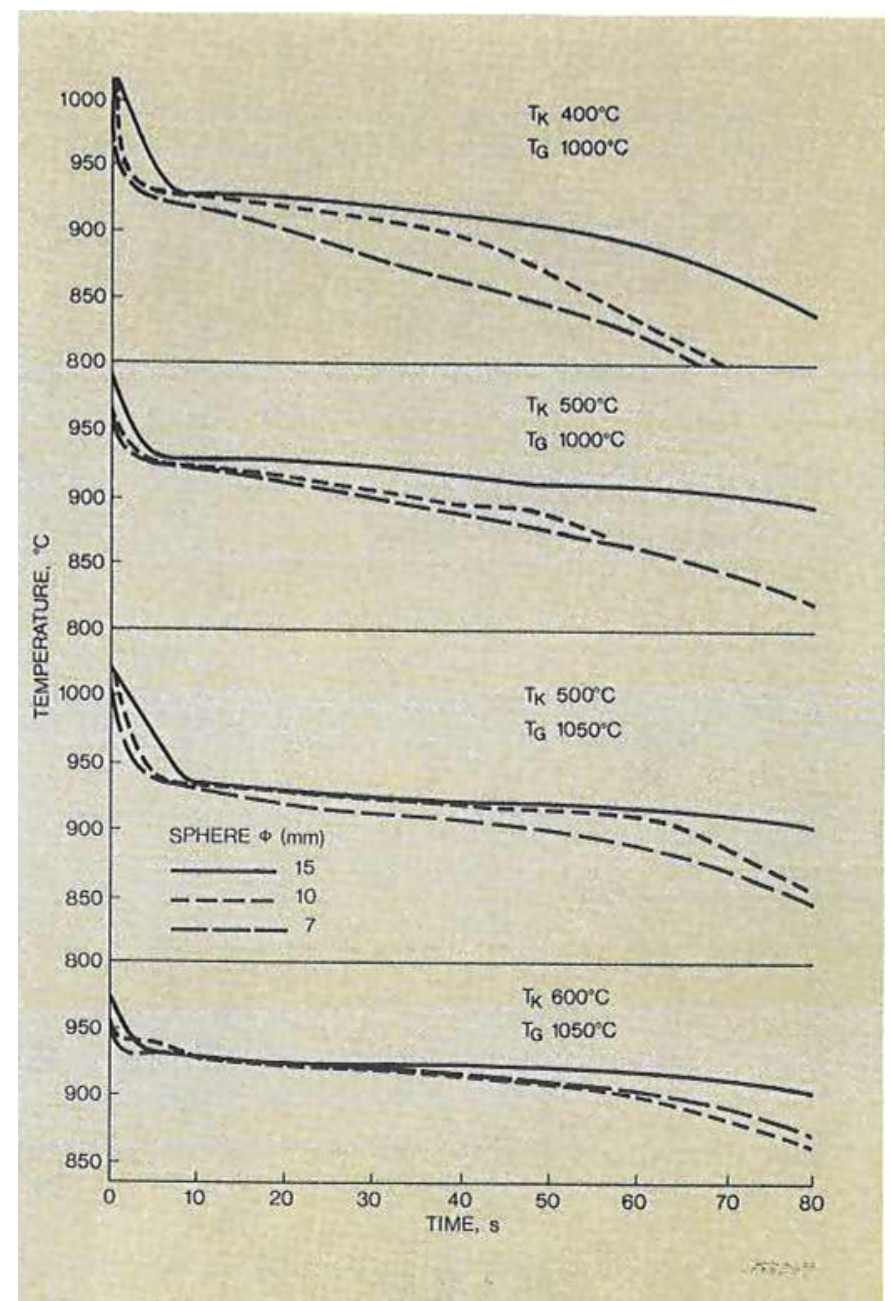

Fig. 2 Variations in temperature with time during the casting of spheres

solidification of the metal was completed could often not be determined in experiments with spheres of smaller diameter.

Analysis of the results revealed no clear relationship between the casting temperature $\left(T_{G}\right)$ and behaviour of the castings on cooling. This may be attributed to the speed with which the melt cooled when it was poured and the differences between the speeds with which cooling occurred when using different casting processes. In order to determine the magnitude of the heat losses, not only were temperatures taken directly in the melt on pouring, but also the maximum temperatures reached by the spheres were determined. Various casting procedures were used including vacuum-assisted casting, in which the melt was released either (a) from the bottom of the crucible or, (b) by pouring over the edge of the crucible. In tests using equipment of the latter type, the temperature of the melt was also determined in the trunk of the casting tree close to its point of entry.

The results are set out in Table I. Under comparable conditions 


\section{Table I}

Results of Temperature Measurements During (a) Vacuum-assisted Casting and (b) Pressure Casting.

\begin{tabular}{|c|c|c|c|}
\hline \multirow[t]{2}{*}{ Technique } & \multirow{2}{*}{$\begin{array}{l}\text { Number of } \\
\text { observations }\end{array}$} & \multicolumn{2}{|c|}{ Temperature Deviation (K) } \\
\hline & & Mean & rd Deviation \\
\hline & & \multicolumn{2}{|c|}{$\left(T_{G}-T_{K u}\right)$} \\
\hline a & 27 & 58 & 19 \\
\hline b & 12 & 120 & 46 \\
\hline b & 22 & 65 & 22 \\
\hline
\end{tabular}

$T_{G}=$ Casting temperature, measured in the melt

$T_{K u}=$ Maximum temperature in the crucible

$T_{\text {st }}=$ Maximum temperature in the sprue (entry port)

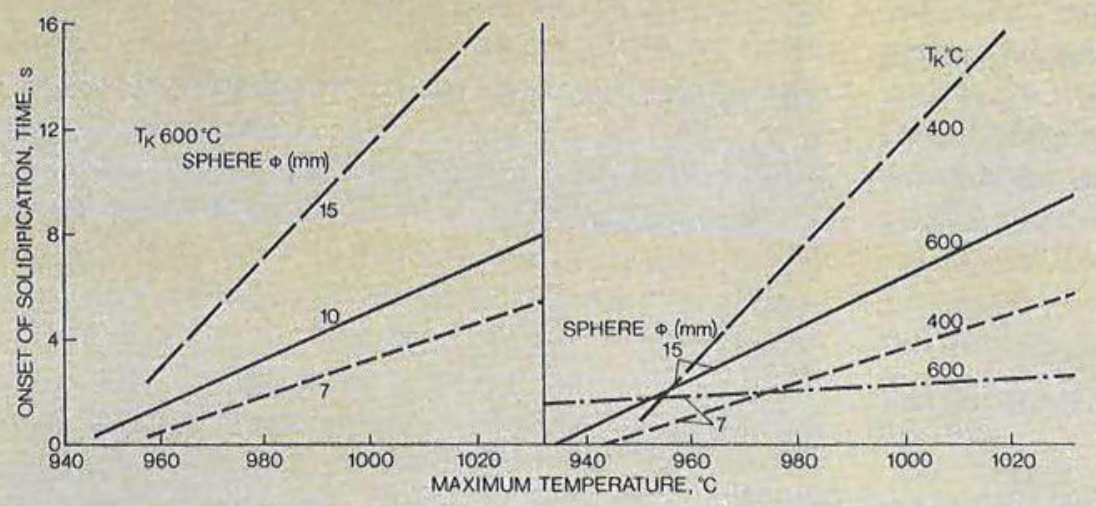

Fig. 3 Dependence of times elapsed before solidification began upon the maximum temperatures measured in spheres during casting

Fig. 4 Dependence of the time elapsed before solidification began upon the surfaceto-volume ratios of spheres during casting

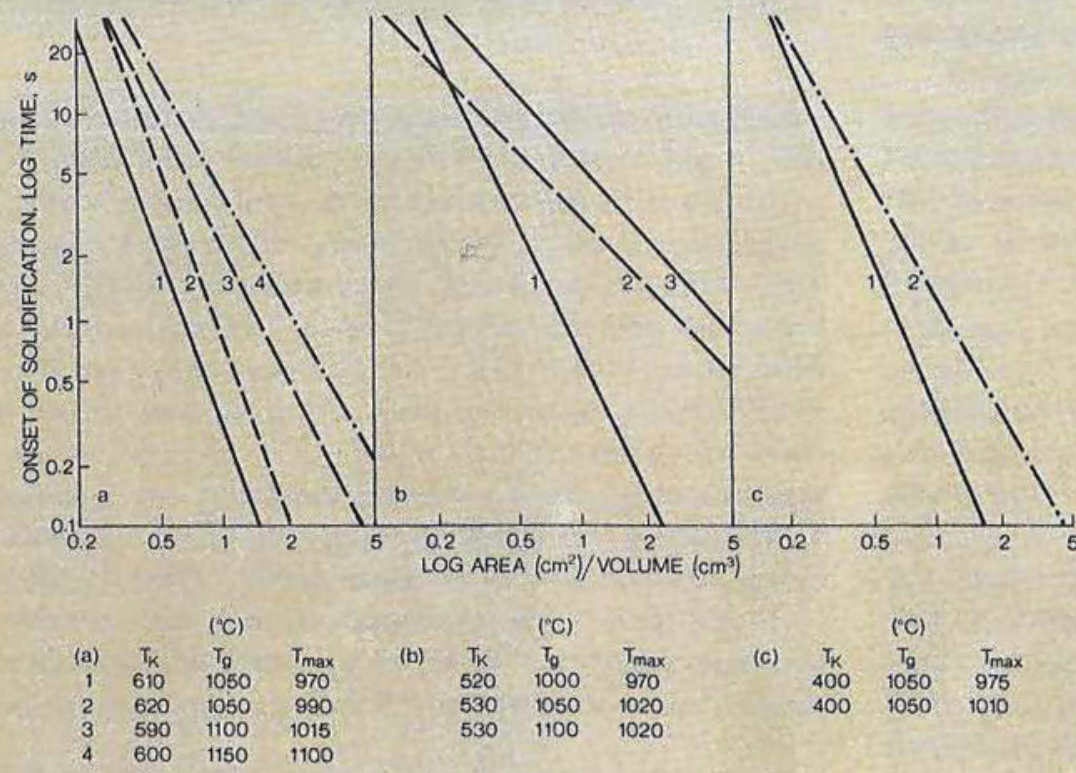

the losses in temperature when casting by method (a) wete only half those which occurred using method (b). Moreover, using method (a) the spread in the experimental results was less. The findings demonstrate that, as a result of unavoidable variations in the cooling of the melts in different casting processes, variations of 50 to $100^{\circ} \mathrm{C}$ in the casting temperature may require compensation. In order to be certain that the temperature of the melt when it reaches the casting vessel is high enough to ensure good filling of the mould, the temperature of the melt and the casting temperature must be chosen so as to be high relative to the liquidus temperature of the metal. The observed temperature of the melt at its point of entry into the casting vessel showed that there is considerable loss of heat from the melt before it reaches the casting vessel.

A significant effect of the mould temperature upon the maximum temperature of the metal in the mould could not be established. Because of this, the maximum temperatures $\left(T_{\max }\right)$ of the metal during the casting of spheres was more closely examined. As Figure 3 shows, an approximately linear relationship was found to exist between the time which elapsed before solidification of the melt began and $T_{\max }$ With a mould temperature of $600{ }^{\circ} \mathrm{C}$ and a $T_{\max }$ of: $1000{ }^{\circ} \mathrm{C}$, which corresponds to a casting temperature of 1050 to $1100^{\circ} \mathrm{C}$, the time which elapsed before solidification began in the mould was between $3 s$ (for spheres $7 \mathrm{~mm}$ in diameter) and $11 \mathrm{~s}$ (for spheres $15 \mathrm{~mm}$ in diameter). A dependence of this time upon the sphere diameter can be observed. In addition an influence of the mould temperature $\left(T_{K}\right)$ on this time is recognizable, especially in the casting of larger diameter spheres at higher values of $T_{\max }$ An influence of the mould temperature on the casting of small diameter spheres is less apparent, probably because of the decreased accuracy of the observations in such casting, and the resultant greater spread in the experimental results. In this connection, the small times elapsing before the start of solidification and supercooling of the melt, which was often observed and which delayed the onset of solidification, are factors which cannot be ignored.

A possible relationship between $T_{\max }$ and the solidification time (i.e. the time 
interval between the onset and the end of the solidification process) was also sought but was not found. Both the sphere diameter and the mould temperature appear to influence the solidification time, but the relationships are not always clearcut. Higher mould temperatures and greater sphere diameters were associated frequently, but not always, as might be expected, with larger solidification times, which varied from 10 to $100 \mathrm{~s}$.

Figure 4 illustrates, on a logarithmic scale on both axes, the dependence of the time to onset of crystallization $\left(t_{I}\right)$ upon the surface-to-volume ratio $R\left(\mathrm{~mm}^{-1}\right)$. This accords approximately with the equation:

$$
\text { or } \begin{aligned}
\log t_{\mathrm{L}} & =\mathrm{A}-\mathrm{B} \cdot \log \mathrm{R} \\
\mathrm{t}_{\mathrm{L}} & =\mathrm{C} \cdot \mathrm{R}^{-\mathrm{B}}
\end{aligned}
$$

where $A, B$ and $C$ are constants.

This approximately linear relationship was observed in all tests, the positions and slopes of the plotted lines, i.e. the values of the constants $A$ and $B$ varying from experiment to experiment. The values of $T_{\max }$ and $T_{K}$ had considerable influence. Analyses of the results show that the time to onset of crystallization is of the order of tenths of a second. In casting practice, where the values of $R$ for castings are less favourable, still shorter times are to be expected. In the light of these facts, the filling of the mould must take place exceedingly rapidly.

Temperatures in the Investment Material The temperature changes in the investment material at various distances from the surfaces of cast spheres, as well as the cooling curves of the spherical castings, are illustrated in Figure 5. Irrespective of differences caused by variations in the values of $T_{\max }, T_{K}$ and the diameter of the cast sphere, the following picture of the course of events emerges:

The temperature of the investment material increases approximately linearly with the logarithm of the time. Nevertheless during the short interval up to the onset of solidification the temperature of the investment material changes only within distances of 1 to $2 \mathrm{~mm}$ from the casting. This is the case even in the casting
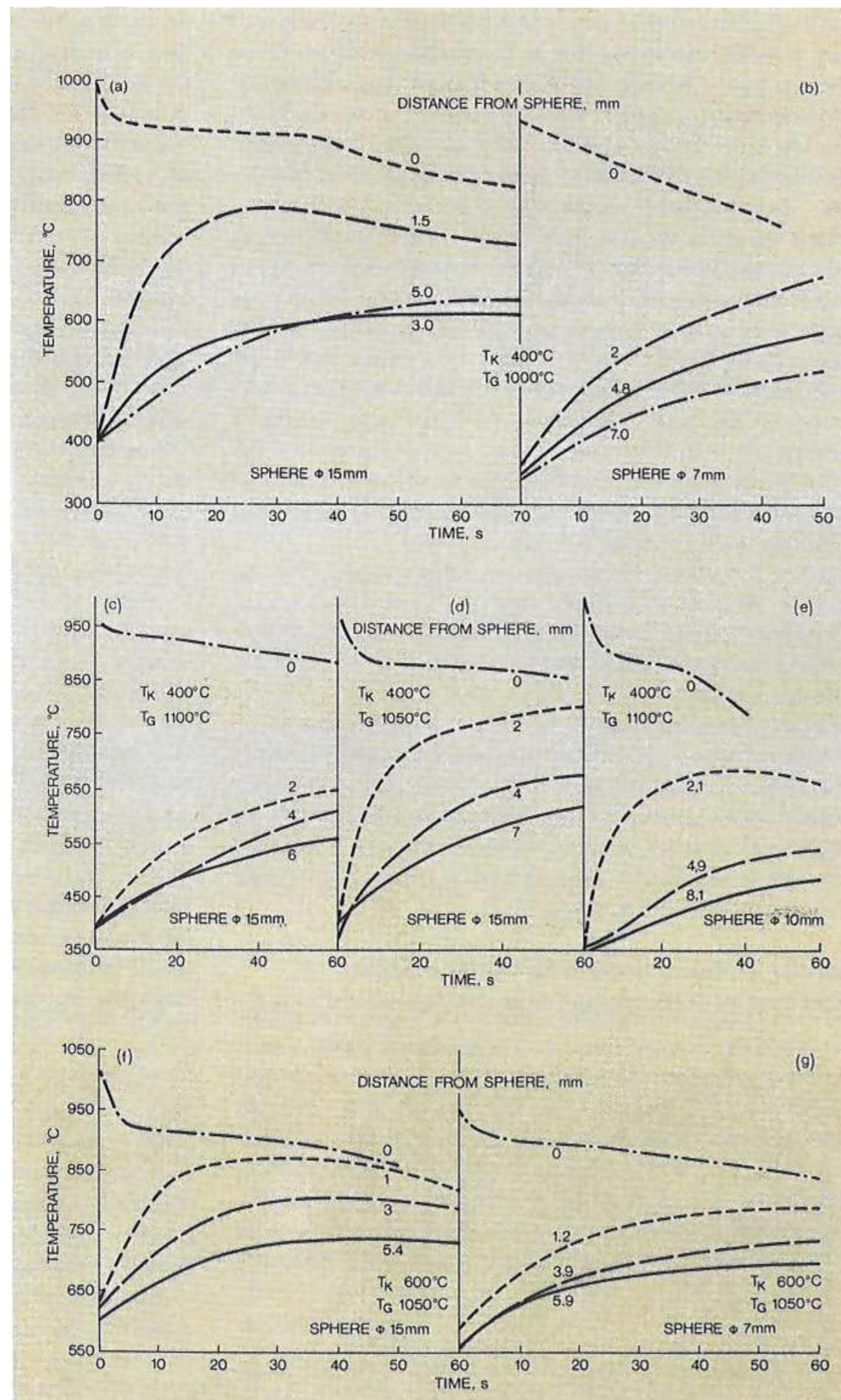

Fig. 5 Dependence upon time of the temperature changes occurring in the investment at various distances from the surfaces of spheres during their casting 
of spheres of diameter $15 \mathrm{~mm}$, which are large in comparison to items normally cast in practice. In immediate proximity to the sphere, it is only after a period of more than $30 \mathrm{~s}$ that a maximum temperature is reached and this is up to $400{ }^{\circ} \mathrm{C}$ above the initial temperature of the casting vessel. Moreover, with few exceptions, the solidification of the casting is already completed within this time. The low thermal conductivity of the investment material hinders any rapid escape of heat. It is therefore unlikely that, in casting a number of items on the same tree, they will affect each other's solidification. However, the measurements show clearly that within a distance of 1 to $2 \mathrm{~mm}$ from larger sized castings, temperatures develop during solidification which exceed the temperature at which decomposition of calcium sulphate occurs. It must also be borne in mind that the critical temperature for decomposition may be lowered in contact with the liquid metal and in the reducing atmosphere. The faults which occur in castings made under unfavourable conditions can thus be simply explained as arising from the formation of sulphur dioxide.

The temperature rise in the investment material, relative to the initial temperature of the casting vessel and plotted as a function of the distance from the surface of a sphere, is illustrated in Figure 6. The measurements were made at a time of $30 \mathrm{~s}$ after filling of the mould.

The temperature rises approximately parabolically and it is to be noted that neither the original temperature of the casting vessel nor the diameter of the cast sphere (and therefore the surface-to-volume ratio of the casting) have any significant effect on the course of the temperature rise in the investment mass. The observed variations were always within the large spread of values which were characteristic in tests of this type.

\section{Temperature Measurements in the Casting of Spirals}

Some results of temperature measurements made during the casting of spirals are given in Figure 7 . The most striking feature of them is the sharp drop in temperature with increasing distance from the feed point on the trunk of the casting tree. This was on average as high as $70 \mathrm{~K}$ between the trunk and the first observation point about $100 \mathrm{~mm}$ along the spirals. It was therefore of the same order as the difference between the temperature of the melt on casting and its temperature at the inlet to the casting tree.

After the molten metal has flowed a further distance of about 100 $\mathrm{mm}$ to the second observation point its temperature has dropped a further 70 to $80 \mathrm{~K}$ on average and is then close to that at which solidification begins. The results of some studies of the changes in temperature with distance along the spiral are given in Figure 8. In these studies the temperature had dropped sufficiently to start solidification within a distance of, at most, $200 \mathrm{~mm}$ along the spiral. The maximum length to which the spiral mould could be filled by casting was thus $200 \mathrm{~mm}$. The time interval before onset of crystallization was 1 to $2 \mathrm{~s}$, depending upon the positions of the observation points. The solidification time (i.e. the time interval between the onset and the end of crystallization), plotted as a function of the position of the observation points, is also illustrated in Figure 8. Even at the outer observation points, it is still only a few seconds. A result of the rapid cooling which occurs is that of frequent supercooling. The fall in temperature of the melt as it flows into the spiral is on average $0.7 \mathrm{~K} / \mathrm{mm}$, though in individual experiments rates varying from 0.2 to $1.0 \mathrm{~K} / \mathrm{mm}$ were observed. The duration of the filling process is of the order of 0.1 to $0.5 \mathrm{~s}$. If one assumes an average temperature drop of $50 \mathrm{~K} / \mathrm{mm}$ between observation points and a time of $0.2 \mathrm{~s}$ for the duration of the inflow of molten metal, then one arrives at the very high figure of $250 \mathrm{~K} / \mathrm{s}$ for the rate of cooling during metal inflow. These figures are only approximate, but it is nevertheless clear that a speeding up of the filling of the mould by increasing the gas permeability of the investment, or by externally applied pressure, should increase the extent of

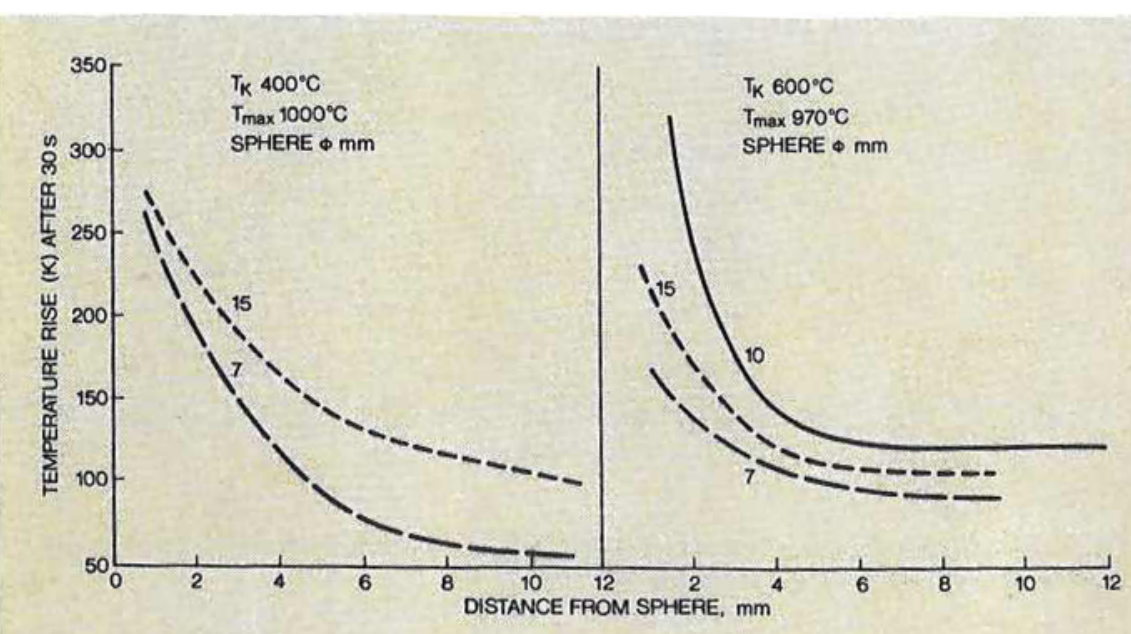

Fig. 6 Temperature changes in the investment, at various distances from the surfaces of spheres, $30 \mathrm{~s}$ after testing 


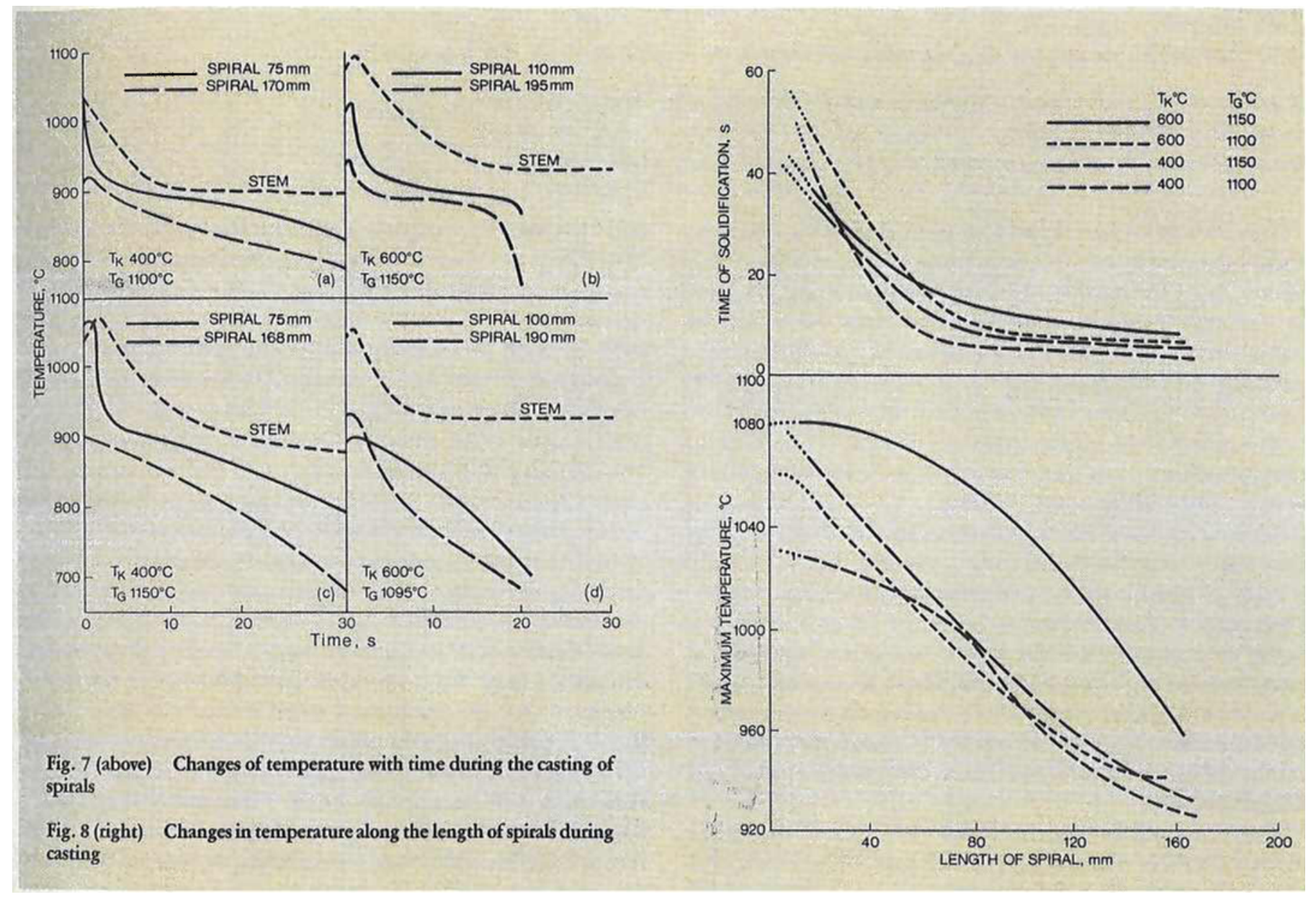

penetration of the molten metal before the onset of solidification and therefore the extent to which the mould is filled.

\section{Summary}

The temperature measurements which have been made in the metal and in the investment material during casting of the yellow 18-carat gold alloy show that the falls in temperature which take place in the metal during pouring and during flow into the mould vary considerably and are determined primarily by the technique used in casting. The temperature of the melt before it is poured is not a reliable parameter in comparative studies. The time interval before the onset of solidification of the metal varies almost linearly with the maximum temperature observed in it in the mould. Nevertheless no clear dependence upon this temperature of the time taken for the metal to solidify can be observed.

There is a linear relationship between the time interval to onset of solidification and the specific surface-to-volume ratio $R$ of the casting when each of these parameters is plotted on a logarithmic scale. The low thermal conductivity of the investment has as a consequence that, within distances of greater than $3 \mathrm{~mm}$, even from large castings, significant rises in temperature develop only after time intervals which considerably exceed the solidification time of the melt. Mutual interaction, in respect of their solidification, between different castings made on the same tree is therefore unlikely.

Sharp falls in temperature occur in the metal during its flow into the mould. In the casting of a wire spiral with a wire diameter of 2 $\mathrm{mm}$ the rate of temperature drop was about $0.7 \mathrm{~K} / \mathrm{mm}$.

\section{Acknowledgement}

The authors thank the International Gold Corporation Limited, Johannesburg, and in particular Drs. G. Gafner and W.S. Rapson of the organisation, as well as the Arbeitsgemeinschaft Industrieller Forschungsvereinigungen eV., Köln and firms involved in the German jewellery industry for their support of the above research. They also wish to thank a number of manufacturers of investment materials and casting equipment for generous assistance.

This article is the penultimate in a series on investment casting of gold alloys published in recent issues of Gold Bulletin, and also in Metall, in German. 